\title{
A mechanically-induced colon cancer cell population shows increased metastatic potential
}

Xin Tang ${ }^{1}$, Theresa B Kuhlenschmidt ${ }^{2}$, Qian $\mathrm{Li}^{3}$, Shahjahan Ali ${ }^{4}$, Stephane Lezmi ${ }^{2}$, Hong Chen ${ }^{3}$, Melissa Pires-Alves ${ }^{2}$, William W Laegreid ${ }^{2}$, Taher A Saif ${ }^{*}$ and Mark S Kuhlenschmidt ${ }^{2^{*}}$

\begin{abstract}
Background: Metastasis accounts for the majority of deaths from cancer. Although tumor microenvironment has been shown to have a significant impact on the initiation and/or promotion of metastasis, the mechanism remains elusive. We previously reported that HCT-8 colon cancer cells underwent a phenotypic transition from an adhesive epithelial type (E-cell) to a rounded dissociated type (R-cell) via soft substrate culture, which resembled the initiation of metastasis. The objective of current study was to investigate the molecular and metabolic mechanisms of the E-R transition.
\end{abstract}

Methods: Global gene expressions of HCT-8 E and R cells were measured by RNA Sequencing (RNA-seq); and the results were further confirmed by real-time PCR. Reactive oxygen species (ROS), anoikis resistance, enzyme activity of aldehyde dehydrogenase 3 family, member A1 (ALDH3A1), and in vitro invasion assay were tested on both $\mathrm{E}$ and R cells. The deformability of HCT-8 E and R cells was measured by atomic force microscopy (AFM). To study the in vivo invasiveness of two cell types, athymic nude mice were intra-splenically injected with HCT-8 E or R cells and sacrificed after 9 weeks. Incidences of tumor development and metastasis were histologically evaluated and analyzed with Fisher's exact test.

Results: Besides HCT-8, E-R transition on soft substrates was also seen in three other cancer cell lines (HCT116, SW480 colon and DU145 prostate cancer). The expression of some genes, such as ALDH3A1, TNS4, CLDN2, and AKR1B10, which are known to play important roles in cancer cell migration, invasion, proliferation and apoptosis, were increased in HCT-8 R cells. R cells also showed higher ALDH3A1 enzyme activity, higher ROS, higher anoikis resistance, and higher softness than $\mathrm{E}$ cells. More importantly, in vitro assay and in vivo animal models revealed that HCT-8 R cells were more invasive than E cells.

Conclusions: Our comprehensive comparison of HCT-8 E and R cells revealed differences of molecular, phenotypical, and mechanical signatures between the two cell types. To our knowledge, this is the first study that explores the molecular mechanism of E-R transition, which may greatly increase our understanding of the mechanisms of cancer mechanical microenvironment and initiation of cancer metastasis.

Keywords: In vitro cancer microenvironment, Metastasis, Mechanotransduction, Cancer biomarkers, Invasiveness, Polyacrylamide hydrogel

\footnotetext{
* Correspondence: saif@illinois.edu; kuhlensc@illinois.edu

'Department of Mechanical Science and Engineering, College of

Engineering, University of Illinois at Urbana-Champaign, 206 W. Green St,

Urbana 61802, Illinois, USA

${ }^{2}$ Department of Pathobiology, College of Veterinary Medicine, University of Illinois at Urbana-Champaign, 2001 S. Lincoln Ave, Urbana 61802, Illinois, USA

Full list of author information is available at the end of the article
} 


\section{Background}

During metastasis, cancer cells escape from the parent tumor, enter the circulatory system, invade host tissues, and form secondary tumors [1-3]. Deciphering the mechanisms initiating metastasis remains elusive due to the difficulty of studying the early stages in vivo [3-5]. Cancer cells within the same tumor show a large degree of heterogeneity $[4,6]$ and thus, it is possible that a small fraction of the parent tumor cells are more plastic or stem-like than most others. With appropriate mechanical cues, such as a change in substrate stiffness within the emergent tumor microenvironment, these cells could differentiate into metastatic variants $[7,8]$. Alternatively, a small population of preexisting metastatic cell variants may be selected for expansion under the influence of appropriate tumor microenvironment [9].

Towards this end, various cancer cell lines, for example those derived from human colon cancer tumors, have been used for in vitro studies. Many of these colon cancer cell lines with low metastatic potential (e.g., HCT-8, HCT-116, HT29) are epithelial in phenotype (E cell). When cultured on conventional plastic substrates, they adhere and spread, proliferate, and form E-cadherin-mediated junctions resulting in monolayers covering the entire dish with occasional mounds consisting of 2-3 layers of cells. On top of these mounds or at their vicinity, a variant of the cancer cells is detected [10-14]. These variant cells are spherical in shape, and rare in number ( 1 rounded-shaped cell per $2 \times 10^{5}$ epithelial-shaped cells). They are called $\mathrm{R}$ cells due to their rounded morphology $[10,12,13]$. Remarkably, the proportion of these $R$ cell variants can be increased by a few orders of magnitude by culturing E cells on appropriately soft substrates. Under these culture conditions $70-90 \%$ of the original $\mathrm{E}$ cell layers transit to $\mathrm{R}$ cells after 17-20 days in culture.

Increasing evidence suggests the mechanical microenvironment plays a role in cancer metastasis [15-20]. For example, a stiffer microenvironment, induced by increased collagen crosslinking in breast cancer tumors in vivo, promotes initiation of metastasis [21,22]. An appropriately soft fibrin gel microenvironment produces a metastatic variant of murine B16-F1 melanoma cells that are highly tumorigenic in animal models [23]. It is known that cells generate forces that depend on the stiffness of the microenvironment $[20,24,25]$. Thus tumor mechanical microenvironments may influence metastatic transition through local force cues that generate or select a subset of metastatic cells. It is then conceivable the multicellular mounds of HCT-8 cells originally observed in conventional cell culture, might have provided a soft microenvironmental niche that facilitated the production of $\mathrm{R}$ cells [10-14]. This hypothesis is substantially strengthened by our observation of mass scale production of $\mathrm{R}$ cells from E cells on soft substrates [26,27]. We characterized HCT$8 \mathrm{R}$ and $\mathrm{E}$ cells by comparing (a) their gene expression profile using RNA-seq, PCR analyses, and selected protein expression using direct enzyme and immunocytochemical analyses, and (b) their in vitro invasiveness using cell invasion assays, and in vivo metastatic activity in mice using a splenic implantation model. The results imply that $\mathrm{R}$ cells are significantly more metastatic than E cells, and the E-R transition induced by growth on soft substrates may offer a new paradigm for simulating the early events of metastasis accelerated by mechanical cues.

\section{Results}

\section{E-to-R transition in other cell lines cultured on soft substrates}

To explore whether E- $\mathrm{R}$ transition is peculiar only to HCT-8 cells, we observed an E-R transition in three other cancer cell lines (HCT116, SW480 colon and DU145 prostate cancer cells) cultured on substrates with various softness. We found colon cancer cell lines, SW480 and HCT116, show E-R transition on 1.0 and 10 $\mathrm{kPa}$ gels, respectively, after 10 days of culture, whereas the prostate cancer cell line, DU145, exhibits E-R transition on $10 \mathrm{kPa}$ gel after 19 days (Figure 1). The time points, e.g. 7th or 19th day, are precisely the earliest dates when the first abrupt phenotype change, i.e. cell rounding and dissociation from some (not all) parent cell islands, was observed after the cells were exposed to soft microenvironment. Following initial observation of cell dissociation in any cell island, the majority of all cell islands showed the E-R phenotype within an additional 1-2 days. On hard polystyrene substrates, none of these cells show E-R transition.

To address the potential bias from the difference in surface chemistry between polystyrene and soft gels, polystyrene substrates were incubated with the identical ECM proteins that were coated on soft gels, i.e. Fibronectin, collagen, and laminin, respectively, and then used for cell culture. No E-R transition was observed on these ECM-incubated polystyrene, or the non-ECM-incubated polystyrene substrates. Previously, we reported that the soft gels with appropriate stiffness consistently gave rise to the E-R transition, irrespective of their ECM functionalization [26,27]. Therefore, we reasoned that, while ECM may possibly play a role in regulating some aspects of the E-R transition, the ECM cue was secondary to the substrate stiffness cue in initiation of this process. The results presented here were obtained using the nonECM-incubated polystyrene.

\section{RNA-Seq analysis reveals overexpression of metastasis- associated genes in $\mathbf{R}$ cells}

To further characterize HCT-8 R cells, we performed comparative differential gene expression analyses following $\mathrm{E}-\mathrm{R}$ transition using whole transcriptome shotgun sequencing (RNA-Seq). Four cell populations, PS3, PS17, 

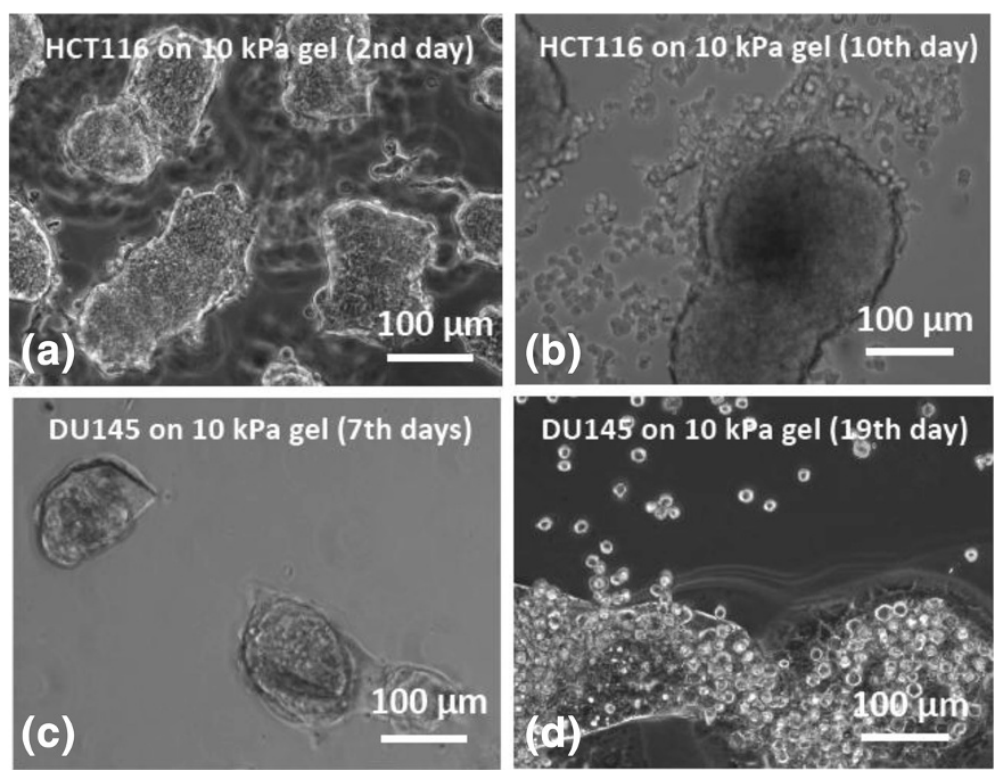

Figure 1 Multiple cancer cells lines show E-R transition on appropriate soft substrates. (a) HCT-116 cells cultured on $10 \mathrm{kPa}$ PA gel substrates (coated with fibronectin) form cell colonies in 2-5 culture days. (b) HCT-116 cells begin to dissociate from colonies on the 10th day. On PS substrate or other stiffness PA gels under same culture condition, they do not show dissociation. (c) DU-145 cells cultured on 10 kPa PA gel substrates (coated with fibronectin) form cell colonies in 3-7 culture days. (d) DU-145 cells begin to dissociate from colonies on the 19th day. On PS substrate or other stiffness PA gels under same culture condition, they do not show dissociation. Scale bar: $100 \mu \mathrm{m}$.

Gel3, and R; under selected temporal-spatial culture conditions were compared. The PS3 and PS17 cell populations are HCT-8 cells cultured on polystyrene (PS) substrate for 3 and 17 days, respectively, without any exposure to soft polyacrylamide (PA) gels. Cells under both conditions display the $\mathrm{E}$ cell phenotype and do not show an E-R transition. The Gel3 cell population is HCT-8 cells cultured on $20 \mathrm{kPa}$ PA gels for 3 days, but still remained in the $\mathrm{E}$ cell phenotype. The $\mathrm{R}$ cell population is derived from HCT-8 R cells harvested from $20 \mathrm{kPa}$ PA gels on $17^{\text {th }}$ day, followed by expansion on PS substrate. In an effort to discover differential gene expression patterns in $\mathrm{R}$ cells due specifically to the E-R transition, we compared gene expression profiles of $\mathrm{R}$ cells with those of Gel 3, PS3, and PS17 cell populations (cell populations not exhibiting an E-R transition). To be scored as a differentially expressed gene, the gene had to satisfy two criteria; 1 ) observed as differentially expressed in $\mathrm{R}$ cells in all three comparisons ( $\mathrm{R}$ vs Gel3, $\mathrm{R}$ vs PS3, and $\mathrm{R}$ vs PS17), and 2) could not show differential expression when PS17 and PS3 cell populations were compared. In this manner, we focused on the genes that were more likely differentially expressed due to the E-R transition rather than extended culture time on PS or initial exposure to PA.

We found that 11 genes were up regulated by 3 fold or greater in $\mathrm{R}$ cells with respect to those in Gel 3, PS3, and PS17 cells (Figure 1; positive Y axis; q-value $<0.05$ ). These genes are associated with tumor promotion and invasion, repression of apoptosis, cell migration and proliferation, and generation of radical species (Figure 2, Table 1). Noticeably, the colon cancer stem cell marker, ALDH3A1 [28-30], was markedly up regulated in R cells. Two other genes, TNS4 and CLDN2, which are known as clinical markers for colon cancer staging [31-34], also were upregulated in $\mathrm{R}$ cells. Ten other genes also were down regulated by 3 fold or greater in $\mathrm{R}$ cells (negative $\mathrm{Y}$ axis; q-value $<0.05$; Figure 2, Table 1). Their functionalities are associated with promotion of apoptosis, maintenance of tissue homeostasis, anti-proliferation, and tumor suppression (Figure 2). Of all those genes, down-regulation of $\mathrm{CKB}$ gene was reported to promote epithelial-to-mesenchymal transition (EMT) in colon cancer [35]. These data suggest, following culture on the appropriately soft mechanical microenvironment, a metastasis-enhancing gene pattern is activated in $R$ cells and this activation is likely associated with the characteristics of in vivo EMT [3,36,37]. Thus, the E-R transition is exemplified not only by a metastasis-like phenotype, but also a metastasis-like gene expression profile.

\section{RT-qPCR validation of differential gene expression}

To confirm the RNA-Seq results, we used RT-qPCR to verify the differential expression of some selected upregulated genes in $\mathrm{R}$ cells. The representative genes used were ALDH3A1, TNS4, CLDN2, and ALDKETO (Figure 2), and are known to play important roles in cancer 


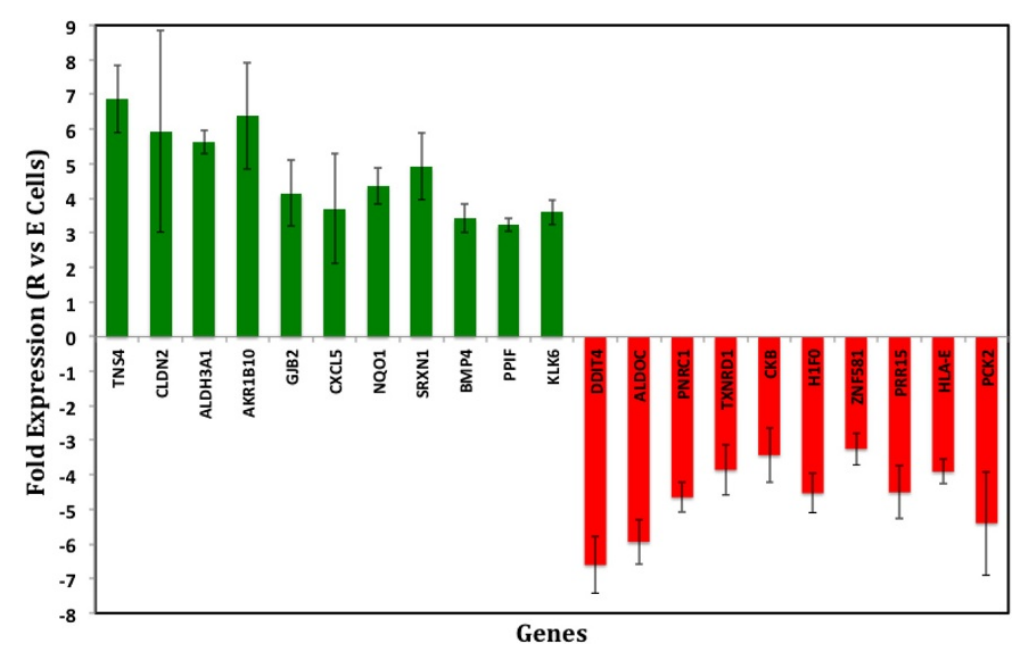

Figure 2 Summary of differentially expressed genes in HCT-8R cells as compared to E cells. RNA-Seq analyses were performed as described in Methods. The data are expressed as fold expression. The bar graph represents the average fold expression changes of $R$ cells compared to E cells cultured under different conditions (PS3, Gel3, and PS17) that do not allow an E to R transition. The graphical and tabulated data summarize the up-regulated (green) as compared to down-regulated (red) genes. The composite results suggest that, most of the differentially up-regulated genes in R cells are associated with the functionalities of cell proliferation, motility, metabolism, invasive phenotype, colorectal adenocarcinoma and tumor metastasis. The differentially down-regulated genes in $\mathrm{R}$ cells are associated with tumor suppression and inhibition of apoptosis.

Table 1 Summary of RNA-seq results showing differentially expressed genes of $\mathbf{R}$ cells compared to $E$ cells

\begin{tabular}{|c|c|c|c|c|c|c|}
\hline GENE ID & GENE & AVG & SEM & R vs PS3 & R vs Gel 3 & R vs PS 17 \\
\hline ENSG00000131746 & TNS4 & 6.87 & 0.964 & 7.94 & 7.24 & 5.42 \\
\hline ENSG00000165376 & CLDN2 & 5.94 & 2.92 & 6.62 & 9.63 & 1.56 \\
\hline ENSG00000108602 & ALDH3A1 & 5.62 & 0.338 & 5.11 & 5.87 & 5.87 \\
\hline ENSG00000198074 & AKR1B10 & 6.38 & 1.53 & 8.67 & 5.19 & 5.26 \\
\hline ENSG00000165474 & GJB2 & 4.14 & 0.952 & 5.27 & 2.71 & 4.44 \\
\hline ENSG00000163735 & CXCL5 & 3.69 & 1.6 & 5.79 & 1.29 & 3.99 \\
\hline ENSG00000181019 & NQO1 & 4.35 & 0.524 & 5.13 & 4.04 & 3.87 \\
\hline ENSG00000172070 & SRXN1 & 4.92 & 0.959 & 6.09 & 5.18 & 3.48 \\
\hline ENSG00000125378 & BMP4 & 3.42 & 0.419 & 2.79 & 4.02 & 3.44 \\
\hline ENSG00000108179 & PPIF & 3.23 & 0.184 & 2.95 & 3.45 & 3.28 \\
\hline ENSG00000167755 & KLK6 & 3.59 & 0.354 & 4.12 & 3.41 & 3.24 \\
\hline ENSG00000168209 & DDIT4 & -6.6 & 0.82 & -7.53 & -5.37 & -6.91 \\
\hline ENSG00000109107 & ALDOC & -5.95 & 0.639 & -5.19 & -6.91 & -5.75 \\
\hline ENSG00000146278 & PNRC1 & -4.66 & 0.432 & -4.01 & -4.83 & -5.13 \\
\hline ENSG00000198431 & TXNRD1 & -3.86 & 0.728 & -3.51 & -3.12 & -4.95 \\
\hline ENSG00000166165 & CKB & -3.44 & 0.792 & -2.25 & -3.54 & -4.52 \\
\hline ENSG00000189060 & H1F0 & -4.54 & 0.566 & -5.39 & -4.06 & -4.16 \\
\hline ENSG00000171425 & ZNF581 & -3.25 & 0.467 & -3.25 & -2.55 & -3.95 \\
\hline ENSG00000087074 & PRR15 & -4.51 & 0.76 & -4.44 & -5.65 & -3.45 \\
\hline ENSG00000204592 & HLA-E & -3.91 & 0.36 & -4.01 & -4.36 & -3.37 \\
\hline ENSG00000100889 & PCK2 & -5.41 & 1.5 & -7.52 & -5.54 & -3.16 \\
\hline
\end{tabular}

The tabulated data compare the fold expression changes [up-regulated (positive values) as compared to down-regulated (negative values) genes] of $\mathrm{R}$ cells compared to E cells cultured under each of the different conditions (PS3, Gel3, and PS17) that do not allow an E to R transition. 
cell de-differentiation, migration, invasion, proliferation and apoptosis suppression [29-34,38-40]. Our qPCR results are consistent with the over-expression of these genes as observed in the RNA-Seq experiments (Figure 3a).

\section{Dissociated $\mathrm{R}$ cells express an enzymatically active cancer} stem cell marker

ALDH3A1 was identified by RNA-Seq and RT-qPCR as over expressed in $\mathrm{R}$ cells. ALDH3A1 has been identified as an important enzyme serving as a marker of various types of cancer stem cells [30,41-43]. In addition to confirming its over-expression in $\mathrm{R}$ cells, we also used direct enzyme activity staining to test whether R cells or E cells on soft substrates possess increased ALDH3A1 enzyme activity. We found greater than $90 \%$ of R cells, as well as a small portion of E cells in the cell islands prior to E-R transition, show high levels of ALDH3A1 (Figure 3b-c). The integrated whole-cell fluorescent intensities of ALDH3A1 for $\mathrm{R}$ cells are 4-5 fold higher than E cells (Figure 3d). These results indicate, in addition to its high mRNA expression, ALDH3A1 enzyme activity is enhanced in $\mathrm{R}$ cells. These results also suggest that in vitro culture on soft substrates may promote the selection or production of cancer stem cells.
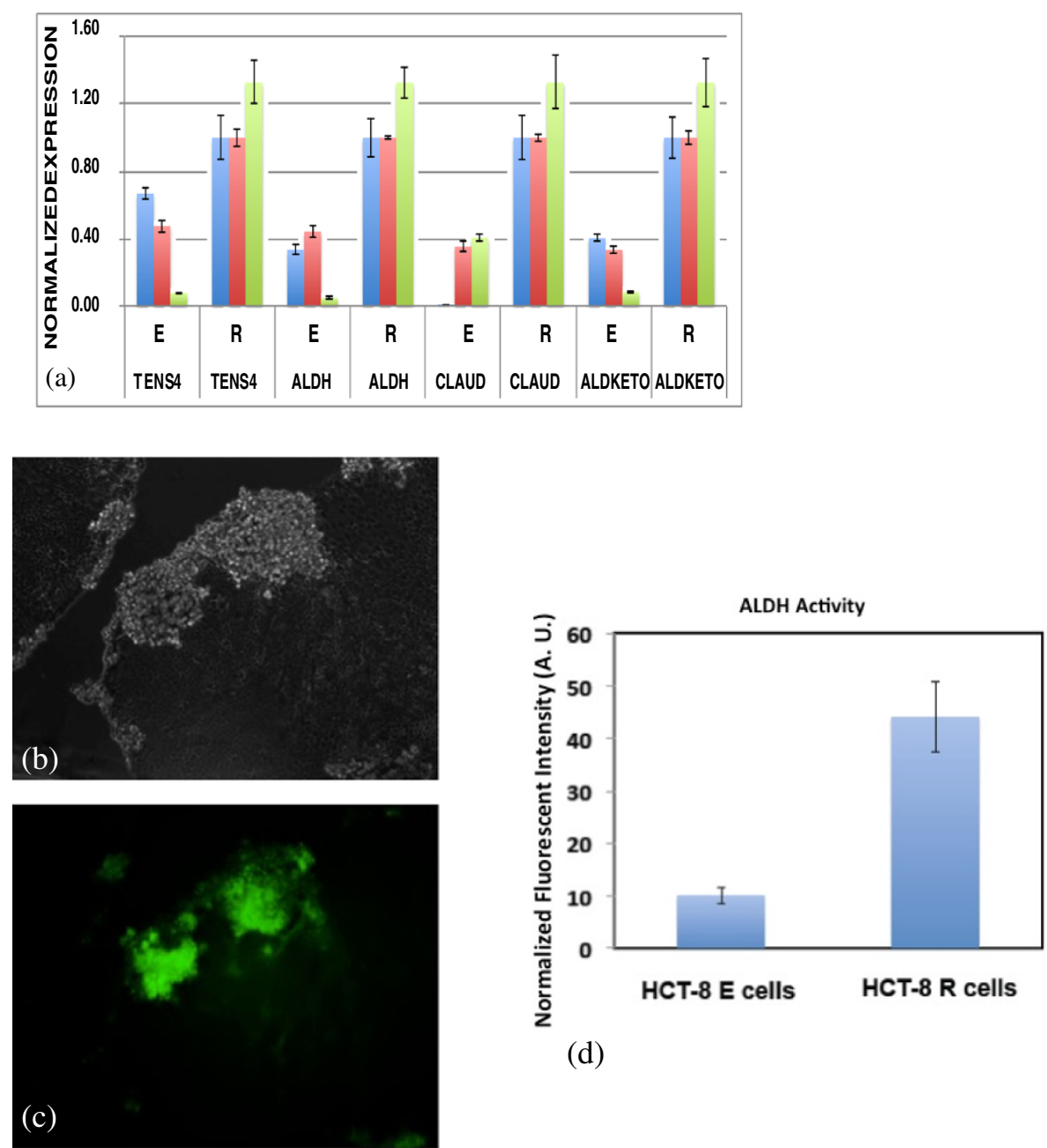

(d)

Figure 3 Verification of selected gene and protein expression. Verification of selected gene and protein expression was performed using RT-qPCR and direct ALDH enzyme-staining assays as described in Methods. (a) RT-qPCR was used to verify overexpression of selected genes identified by RNA-Seq analyses. The blue, pink, and green bars represent 3 separate experiments each consisting of 3 replicate samples for each primer set. One-way ANOVA analyses indicate the mean value increases in gene expression between $E$ and $R$ cells in all experiments for TENS4 $(p<0.03), A L D H 3 A 1(p<0.01), C L D N-2(p<0.01)$ and AKR1B10 $(P<0.005)$ represent statistically significant differences. (b-c) fluorometric ALDH enzyme assays were used to directly measure the relative expression of ALDH in R and $\mathrm{E}$ cells in cell monolayers undergoing $\mathrm{E}-\mathrm{R}$ transition on soft substrates. $90 \%$ of R cells, as well as some E cells in the cell islands undergoing E-R transition express relatively high amounts of ALDH activity. Scale bar: $100 \mu \mathrm{m}$. (d) The integrated cellular fluorescence intensity of ALDH for R cells was 4-5 fold higher as compared to E cells. 


\section{Reactive oxygen species (ROS) production is up regulated in $\mathrm{R}$ cells}

The RNA-Seq gene expression profile showed, following E-R transition, $R$ cells express genes associated with cell survival and inhibition of apoptosis. It is known that the activation of cell survival signaling pathways is often accompanied with the release of ROS from cell mitochondria [44-46]. To determine relative ROS expression, we used a stable fluorogenic marker, 5-(and-6)-carboxy-2', 7' -dichlorodihydrofluorescein diacetate (carboxy- $\mathrm{H}_{2} \mathrm{DCFDA}$ ) to stain both HCT-8 E and R cells followed by imaging using highresolution multi-photon confocal microscopy. The marker distinguishes the oxidatively stressed and non-stressed cell populations through fluorescent-intensity ratiometrics (Figure 4a-c). Our data show $57.8 \pm 5.84 \%$ of $\mathrm{R}$ cells exhibit high ROS expression (fluorescent intensity $=40000 \pm 5000$ (A. U.)). Only $2.32 \pm 1.07 \%$ of $\mathrm{E}$ cells express weak ROS (maximum fluorescent intensity $=5000 \pm 300$ (A. U.)). The integrated whole-cell fluorescent intensity in $\mathrm{R}$ cells is $6-8$ fold higher than in $\mathrm{E}$ cells ( $\mathrm{p}$-value $=0.0001$; Figure $4 \mathrm{c}$ ). It is known that expression of ROS can facilitate cell proliferation, mutagenesis, evasion of apoptosis and malignant transformation $[47,48]$.

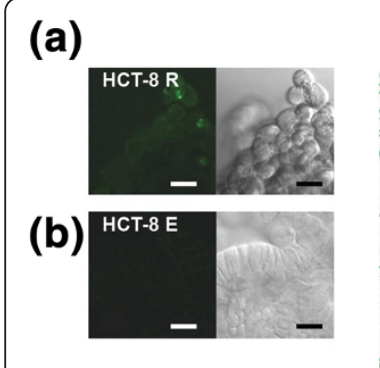

(c)

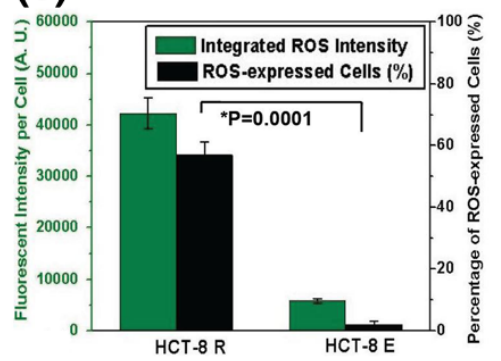

(d)

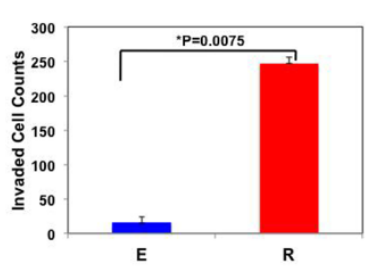

(e)

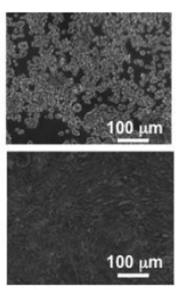

(f)
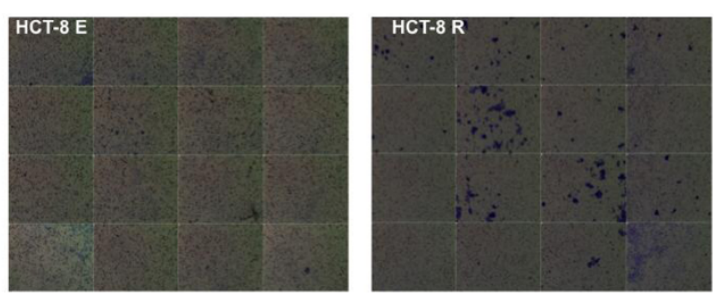

(g)

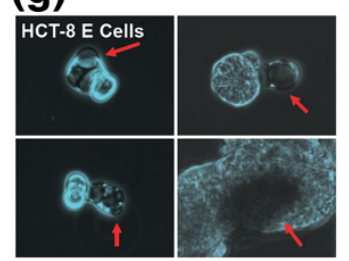

(h)

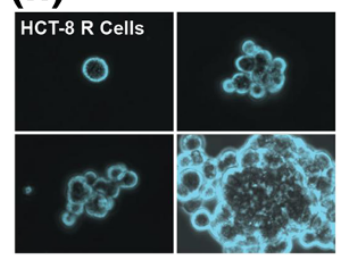

(i)

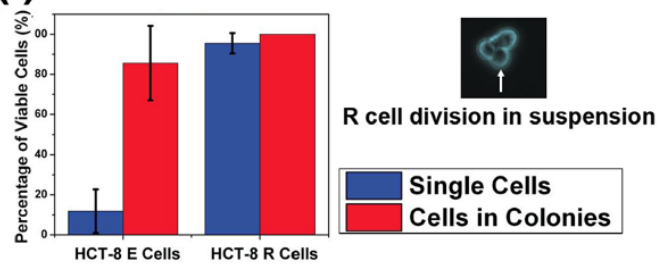

(j)

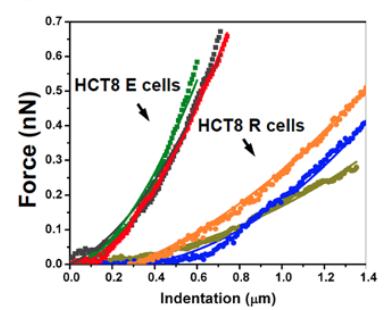

(k)

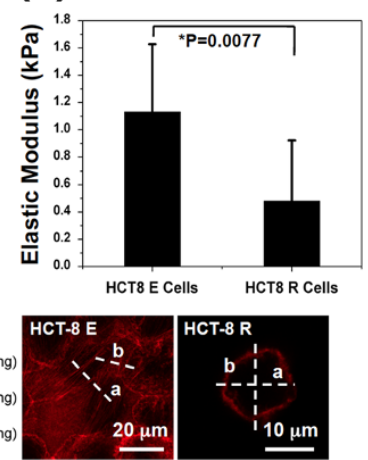

Figure 4 Biophysical properties of E and R cells. (a-b) Reactive oxygen species of HCT-8 E and R cells detected by staining with 5-(and-6)-carboxy-2', 7'-dichlorodihydrofluorescein diacetate. Left: Fluorescent pictures. Right: DIC pictures. Scale bar: $20 \mu \mathrm{m}$. (c) Comparison of ROS production in E and R cells. (d) Comparison of basement membrane invasiveness of $E$ and R cells. R is HCT-8 R cells harvested from $20 \mathrm{kPa}$ gels on after 17 days culture. E is HCT-8 cells cultured on PS for 10 days. (e) Phase-contrast photomicrographs of HCT-8 R (top) and E cells (bottom) cultured on PS prior to harvesting and invasion assay. Scale bar: $100 \mu \mathrm{m}$. (f) Assembled $4 \times 4$ picture set of invaded HCT-8 E cells after $48 \mathrm{hr}$ incubation. Assembled $4 \times 4$ picture set of invaded HCT-8 R cells after $48 \mathrm{hr}$ incubation (purple foci indicates invaded cells). (g-h) Comparison of the anchorage independent growth and viability of HCT-8 $\mathrm{E}(\mathbf{g})$ and R cells after culture on non-functionalized gels for 8 days. The percentages of viable $E$ and $R$ cells were determined by Trypan-blue staining (i). Red arrows in (g) indicate the dead cells. (j) Atomic force microscopy measurement of stiffness of HCT-8 cells before and after E-R transition. The square-dot and circle-dot curves represent the force vs. indentation displacement of HCT-8 E and R cells, respectively. The data were fitted using an improved Hertz model to extract the Elastic modulus of cells. (j) Comparison of the cell elasticity of E and R cells. (k) Comparison of actin organization in E and R cells on PS. Rhodamine phalloidin (520/650, red) was used specifically stain F-actin filaments. The spatial fluorescent intensity distributions of actin expression across $E$ and $R$ cells body are indicated by dashed lines a and b). Scale bar: $10 \mu \mathrm{m}$. 


\section{$R$ cells display enhanced basement membrane invasion}

We compared the invasiveness of $\mathrm{E}$ and $\mathrm{R}$ cells using an in vitro cell invasion assay. HCT-8 $\mathrm{R}$ cells were harvested from $20 \mathrm{kPa} \mathrm{PA}$ gels on $17^{\text {th }}$ culture day following E-R transition and expanded on PS substrates for another 7 days before the invasion assay (Figure $4 \mathrm{~d}-\mathrm{e}$ ). HCT-8 E cells were cultured on PS substrate for 10 days prior to the invasion assay (Figure 4e). The results of these in vitro invasion experiments show that $\mathrm{R}$ cells are significantly more invasive, an essential metastatic phenotype $[3,9,49]$, compared to $\mathrm{E}$ cells: the number of $\mathrm{R}$ cell foci penetrating through basement membranes is more than 10 fold greater than observed with $E$ cells ( $P$ value $=0.0075$; Figure 3d).

\section{R cells acquire anoikis resistance}

A critical step for successful metastasis is the survival of cancer cells in absence of substrate attachment [50]. Normal cells undergo programmed cell death, i.e., anoikis, when kept unattached to a substrate matrix or neighboring cells. Anoikis, a physiologically essential function, prevents detached cells from forming dysplastic colonies at places other than their correct anatomical locations, and ensures tissue homeostasis [50-52]. Metastasizing cancer cells, however, acquire the ability of anoikis resistance and survive even after detaching from the primary tumor; an ability that enhances their dissemination through the circulatory and lymphatic systems $[51,53]$. To test whether HCT-8 R cells have acquired anoikis resistance, we performed cell suspension growth assays for both $\mathrm{R}$ and $\mathrm{E}$ cells. PA gels without any ECM coating were used to culture both cell types for 8 days followed by cell viability measurements. Since ECMfree gel surfaces are inert and non-adhesive, cells do not form any specific or non-specific anchorage and are thus kept in suspension. The anchorage-free growth and viability of cells on gels were confirmed by daily imaging.

After 7 days culture in suspension, $95.4 \pm 5.07 \%$ of single HCT-8 R cells were alive (Figure 4i), and maintained cell proliferation (Figure $4 \mathrm{~h}$ lower panel) throughout this suspension culture period. In contrast, only $11.8 \pm 10.9 \%$ of single HCT-8 E cells were alive after the same period of suspension culture ( $\mathrm{P}$ value $=0.0001$, Figure 4i). As $\mathrm{E}$ cells form aggregates in suspension, their viability increased 7-8 fold, and $85.6 \pm 18.6 \%$ of the E-cell aggregates were alive, indicating that cell-cell contact might trigger certain survival pathways to partially evade anoikis in vitro (Figure 4g) [54]. For R cells in loosely packed aggregates (Figure 4h), their viability was not significantly different from those in single cell form, and their cell division was not impaired due to suspension culture (Figure 4h, lower panel). Furthermore, the $\mathrm{R}$ cell numbers in suspension increased significantly due to sustained proliferation as the suspension culture continued (Figure 4i). These results are consistent with the RNA-
Seq data, indicating $\mathrm{R}$ cells up-regulate apoptosis inhibition gene expression compared to $\mathrm{E}$ cells. The results suggest $\mathrm{R}$ cells are potentially capable of surviving and growing in vivo as would be expected of a metastasizing cancer cell.

\section{R cells are mechanically softer}

Cancer cells with higher metastatic potential generally display greater deformability [55-59], which allows their easy transit through vasculature during metastasis. Thus, we compared deformability of HCT-8 E and R cells using the contact mode of atomic force microscopy (AFM). HCT-8 E and R cells were both cultured on PS substrates under identical environment conditions $\left(37^{\circ} \mathrm{C}\right)$ throughout AFM analysis (Figure 4j, k and Methods section). We found $\mathrm{R}$ cells are 2-3 times softer, with Elastic modulus $=0.47861 \pm 0.44339 \mathrm{kPa}(\mathrm{n}=8)$, than the $\mathrm{E}$ cells with Elastic modulus $=1.13107 \pm 0.49646$ $\mathrm{kPa}(\mathrm{n}=12 ; \mathrm{P}$ value $=0.0077$; Figure $4 \mathrm{j})$. The softened $\mathrm{R}$ cell elasticity agrees with the previously reported altered actin cytoskeleton architecture in R cells [26]. Specifically, on hard PS substrates E cells show well-organized, straight-ordered actin stress bundles within individual cells. In contrast, HCT-8 R cells show only cortical actin structure with no actin stress bundles, implying a more compliant state (Figure 4k).

\section{$R$ cells display increased in vivo metastatic activity compared to E cells}

In order to evaluate in vivo hepatic invasiveness and metastatic potential, HCT-8 E and R cells were surgically injected into the spleen of athymic nude mice. After 910 weeks, all animals were euthanized and sacrificed. Spleen, liver, and other tissues with tumor development (Figure 5a, b, d, and e) were fixed in formalin and embedded in paraffin to prepare histological slides (Figure $5 \mathrm{c}, \mathrm{f}$ ). Incidences of tumor development and metastasis between HCT-8 E and HCT-8 R groups were evaluated with Fisher's exact test. Necropsy and histological evaluations showed $69 \%$ of the mice injected with HCT-8 R cells and 71\% injected with HCT-8 E cells developed tumor(s), indicating a similar rate of tumor implantations/development (Table 2). On the other hand, $73 \%$ of mice injected with HCT-8 R cells had more than one implantation sites and/or metastases, compared to $40 \%$ for mice injected with HCT-8 E cells (Table 2). Regarding liver metastases, there was a mean of 5.1 metastases in the liver of HCT8-R-injected mice and 3.4 metastases in HCT8-E-injected mice (Table 2). The mitotic rate (number of mitoses per $400 \times$ magnification field), reflecting the growth of neoplastic cells in tumors, was identical in both HCT-8 E and HCT-8 R groups (Table 2). Interestingly, the rate of implantation of tumors in mice injected with $\mathrm{E}$ or $\mathrm{R}$ cells were similar. 


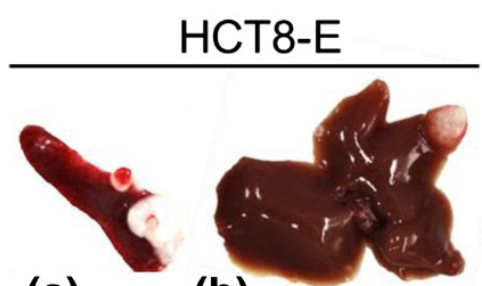

(a)

(b)

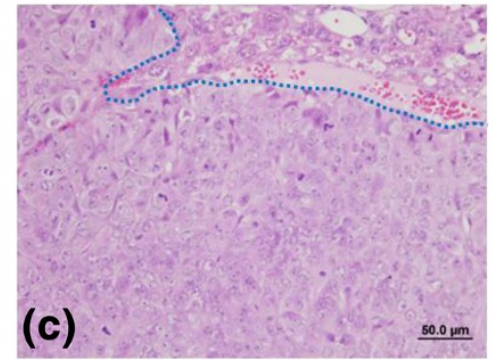

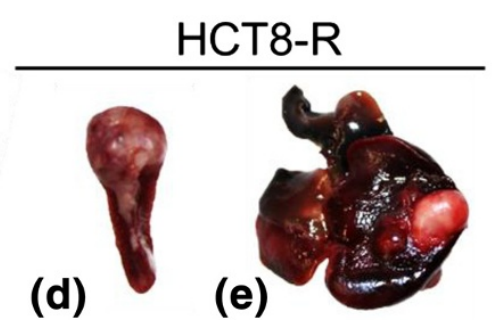

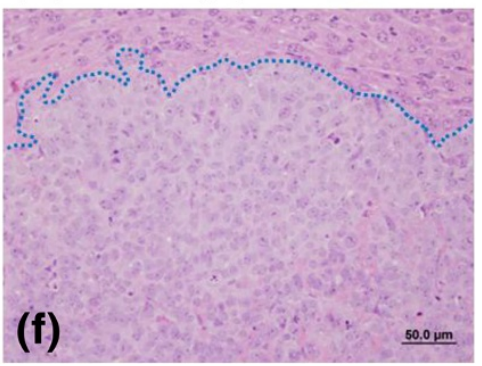

Figure 5 Macroscopic and microscopic aspects of tumors. Macroscopic illustration of tumors in the spleen (a \& d) and liver (b \& e) of HCT8 cell-injected nude mice. $\mathbf{c}$ \& $\mathbf{f}$ illustrate the similar histological growth pattern and cellular morphology of HCT-8E (c) and HCT-8R (f) cells in the liver (H\&E staining, dots show the division of the liver tissue on the top and tumor on the bottom).

Also, there were no morphological differences (growth pattern, stroma collagen production, mitotic index) between $\mathrm{R}$ and $\mathrm{E}$ cell tumors in our vivo model. Thus, the higher rate of tumor implantation with $\mathrm{R}$ cells was not due to cell survival in the spleen after injection or to different growth capacity of neoplastic cells, but likely due to higher migration and invasiveness. These results suggested that HCT-8R cells were more inclined to spread and migrate to different organs compared to E cells.

\section{Discussion}

In this paper, we have demonstrated that soft substrate culture for 7-17 days can elicit remarkable phenotypic and functional changes in HCT-8 colon cancer cells. Soft substrate culture results in a cell population that exhibits a rounded shape, increased basement membrane invasion, anchorage-independent growth, and differential expression of genes associated with increased tumorigenicity, invasiveness, cell survival, and in vivo metastasis. In our in vivo metastatic animal model, HCT-8 R cells acquired strikingly efficient tumorigenic capacity (i.e. capacity to produce tumors in multiple organs) after injection. This mechanicallyinduced transition is not only limited to HCT-8 cells, as we observed the transition in other cancer cells lines as well, although the time to transition and the optimum substrate softness were dissimilar. These results, combined with our molecular data, suggest the $\mathrm{R}$ cells can be reasonably considered as a metastatic cell variant. Similar data were obtained by others with a rounded melanoma cell line, previously cultured on 3D soft fibrin gels, that were highly tumorigenic (tumor development with very low numbers of cells injected subcutaneously or intravenously in mice) [23]. Our model clearly demonstrates that colon cancer R cells, produced from E cells through soft substrate culture, displayed a metastatic phenotype that was not linked to cell survival or mitotic rate of neoplastic cells in vivo. Our results raise the possibility that cells from different origins may undergo an accelerated metastatic transition dependent on their respective optimum mechanical microenvironmental niche.

Our RNA-seq and protein expression analysis showed that a soft mechanical microenvironment stimulated HCT8 cells to express a number of metastasis-enhancing genes associated with functions such as apoptosis inhibition, motility, metastatic activity and cancer stem cell traits. Among those, ALDH3A1, CLDN2 and TNS4 (CTEN), were found consistently up-regulated in R cells, are of particular interest.

Aldehyde dehydrogenases (ALDHs) are cytosolic enzymes responsible for oxidizing aliphatic and aromatic

Table 2 Comparison of tumor development in nude mice

\begin{tabular}{lccccc}
\hline Cell types & Number of animals & $\begin{array}{c}\text { Mice (\%) developing } \\
\text { tumors }\end{array}$ & $\begin{array}{c}\text { Mice (\%) with more than one } \\
\text { implantation site }\end{array}$ & $\begin{array}{c}\text { Mean number of metastases } \\
\text { in the liver }\end{array}$ & $\begin{array}{c}\text { Mean mitotic } \\
\text { rate }\end{array}$ \\
\hline HCT8-E & 7 & $71(5 / 7)$ & 40 & 3.4 & $7.6 \pm 2.0$ \\
HCT8-R & 16 & $69(11 / 16)$ & 73 & 5.1 & $7.3 \pm 2.7$ \\
\hline
\end{tabular}

HCT8-E and HCT8-R cells were injected into the spleen of nude mice as described in Methods. Spleen tumor implantation and liver metastases numbers were based on the evaluation of H\&E stained slides following 9-10 weeks after injection. 
aldehydes to carboxylic acids. The expression of the ALDH isoform 3A1 (ALDH3A1) has been used as a cancer stem/progenitor marker from multiple organs, including colon and liver [39,60-64]. High ALDH3A1 expression and activity have also been found to be closely correlated with cell proliferation [65], increased cell metabolism [66], and prevention of apoptosis [30,41]. Interestingly, in our model, R cells showed prolonged survival in suspension, and resistance to apoptosis with high elevation of ROS that likely correspond to acquired important traits for successful metastasis.

CLDN2 is a transmembrane protein that has been shown to result in epithelial permeability, neoplastic transformation, significant increases in cell proliferation and anchorage-independent growth when overexpressed in colorectal cancer cells [32]. CTEN plays an essential role in regulating the integrin-actin cytoskeletal organization and enhancing cancer cell motility and anchorage-independent growth [33,67]. Interestingly, CTEN lacks the N-terminal actin binding domain and its induction has been associated with a reduction in E-cadherin protein expression (but not the amounts of E-cadherin mRNA) [31] as well as displacement of tensin-3 from the cytoplasmic tail of integrin $\beta_{1}$ causing actin fiber dissociation and increased cell motility, invasiveness, and metastasis [33]. These results parallel our previous observation of HCT-8R cells reducing E-cadherin expression $[26,27]$ and the current observation of the $\mathrm{R}$ cells showing a 7 -fold increase in CTEN mRNA expression. Taken together, these results are consistent with the hypothesis that a switch toward CTEN rather than tensin-3 expression is associated with increased colon cancer cell metastasis.

Interestingly, in human patients affected with colon carcinoma, these genes (ALDH3A1, CLDN2 and CTEN) also have been associated with poor clinical outcomes. Indeed, ALDH3A1 expression and activity has been found to be closely correlated with resistance to apoptosis induced by cytotoxic effects $[65,68]$ or by some chemotherapeutic agents, such as cyclophosphamide [69,70] and oxazphosphorines [71]. The analysis of mRNA and protein expression using a total of 309 patient samples revealed that CLDN2 expression is significantly increased in colorectal cancer, and correlates with cancer progression and tissue invasion [32,33,67]. It has also been reported that colon cancer tumors with higher CTEN mRNA expression display a poorer histological grade, deeper serosa invasion, and more positive lymph node metastasis or peritoneal dissemination. Multivariate analysis also revealed high CTEN mRNA expression could serve as poor prognostic predictor for colon cancer staging [34].

It is rather surprising to discover that HCT-8 R cells harvested following weeks of culture on soft substrates show in vitro irreversibility of their rounded morphology and altered expression of proteins such as E-Cadherin and actin cytoskeleton filaments [26,27]. This interesting phenomenon raises another question: Is it a transition or selection process promoted by soft substrates? Instead of initiating E-R transition de novo, it is possible that soft substrates might enhance the selection of a pre-existing $\mathrm{R}$ cell population that possesses the rounded morphology and invasive characteristics seen in our results. The results of RNAseq analyses, qPCR, and enzyme activity studies consistently show that $\mathrm{R}$ cells express the cancer stem cell marker ALDH3A1. Recently it was reported that an appropriately soft fibrin gel microenvironment selects a metastatic variant of murine B16-F1 melanoma cells that possess the traits of cancer stem cells and are highly tumorigenic in animal models [23]. During culture of HCT-8 E cells in standard tissue culture flasks, we and other independent groups [10-14] also showed that a few rounded isolated cells (R-like cells) appeared only on top of confluent epithelial monolayer (E cells). Although future work is needed to investigate the similarity between pre-existing $\mathrm{R}$ cells and $\mathrm{R}$ cells produced by $\mathrm{E}-\mathrm{R}$ transition and dissociation from E-cell islands on soft gels, we cannot rule out the intriguing possibility that soft substrates might enhance the selection and proliferation of a pre-existing stem-like R cell population. Stem-like $\mathrm{R}$ cells, instead of epithelial-like E cells, might have preferred proliferation on the mechanically soft microenvironment. This hypothesis; however, appears to somewhat contradict our experimental observations showing that only $\mathrm{R}$ cells were present on soft PA gels after 2-3 weeks of culture, while there were nearly no E cells remaining. It seems unlikely that a selection process would result in almost complete elimination of the E cell population. Furthermore, the morphological appearance of R-cell generation from the edge of E-cell islands (26) appears more consistent with a conversion (E-R transition) than a selection process. Nevertheless, it is quite possible that both a selection and a transition processes might co-exist.

The underlying mechanism by which cancer cells sense the microenvironment and decide their metastatic fate remains elusive, but inter- and intracellular forces are likely to play critical roles. The metastatic transition we have demonstrated in vitro immediately enables us to explore the physical-molecular mechanisms of the tumor microenvironment that may initiate the metastatic journey of cancer cells by turning on the necessary molecular pathways. Understanding these mechanisms may lead to the engineering of novel therapeutic drugs capable of inhibiting the initiation of metastasis, for example by blocking the downstream molecular pathways up regulated by the changing tumor mechanical microenvironment. Furthermore, new molecular biomarkers may be developed for rapid, earlier detection and monitoring of metastatic activity. 


\section{Conclusions}

Our comprehensive, comparative investigation reveals HCT-8 R cells are remarkably more invasive and tumorigenic compared to $\mathrm{E}$ cells. The $\mathrm{R}$ cells express many of the molecular signatures associated with resistance to hypoxia, apoptosis, as well as genes linked to metastasis and poor clinical outcome in colon cancer patients. This $\mathrm{E}-\mathrm{R}$ transition, accelerated by in vitro mechanical cues, may mimic the early stages of metastasis, which are difficult to study in vivo. The study presented here suggests mechanical forces within the tumor microenvironment may play a pivotal role in early metastatic transition, and such mechanical environments can be mimicked in an in vitro model. Such in vitro models may enable us to identify the early cellular, mechanical, biophysical, molecular and genetic events responsible for initiation of cancer metastasis, assess the relative metastatic potential of cells obtained from patient biospecimens, identify molecular markers for early diagnosis, and to screen putative therapeutics for inhibition of metastasis.

\section{Methods \\ Cell culture}

Human colon adenocarcinoma HCT-8 cells (Cat. No. CCL244; ATCC, Manassas, VA) were cultured as previously described $[26,27,72]$. Human colon adenocarcinoma SW480 cells (Cat. No. CCL-228; ATCC, Manassas, VA) were cultured in L-15 Medium (Cat. No. 30-2008; ATCC) supplemented with $10 \%$ fetal bovine serum and Penicillin Streptomycin. Human colon carcinoma HCT-116 cells (Cat. No. CCL-247; ATCC, Manassas, VA) were cultured in McCoy's 5a Medium (Cat. No. 30-2007; ATCC) supplemented with $10 \%$ fetal bovine serum and $1 \times$ antibiotic-antimycotic (Cat. No. 15240-062; Gibco). All cells were cultured at $37^{\circ} \mathrm{C}$, with optimal humidity and $5 \% \mathrm{CO} 2$.

\section{PA gels preparations and AFM calibration}

Polyacrylamide (PA) gels were prepared following the protocols described [26,73-76]. The PA gels are made with varied relative concentrations of acrylamide (BioRad) and N, N'- methylene bis-acrylamide (Bio-Rad Inc.) to obtain different cross-link percentages resulting in different elastic moduli. For $20 \mathrm{kPa}$ PA gels, the mol/v concentrations of acrylamide and N, N'- methylene bisacrylamide are $8 \%$ and $0.13 \%$, respectively. All gels, except the ones used for suspension tests, were covalently coated with $25 \mu \mathrm{g} / \mathrm{mL}$ fibronectin (BD Science Inc.). Atomic force microscopy (Asylum), with silicon-nitride cantilever having a spring constant $\mathrm{k}=148.14 \mathrm{pN} \times \mathrm{nm}-1$ (Veeco) and equipped with the environmental chamber, was used to characterize the stiffness of PA gels as well as HCT-8 E and R cells. A conical tip approximation for the
AFM tip was used to extract the Elastic modulus of cells and gels [26,77].

\section{Basement membrane invasion assay}

HCT-8 E cells were grown and HCT-8 R cells were produced on soft PA gel substrates $(20 \mathrm{kPa})$, and harvested as previously described [26,27]. During harvesting, the $R$ cells from PA gels were flushed from the gel surface using sterile culture media and filtered using a sterile $40 \mu \mathrm{m}$ mesh filter (BD Falcon \#352340) to remove primarily residual $\mathrm{E}$ cell clusters. E cells and R cells (following expansion on PS for 7 additional days) were harvested with trypsin EDTA and all cell populations adjusted to the same starting concentration $(7 \times 106$ cells per $\mathrm{ml})]$. Aliquots $(0.3 \mathrm{ml})$ of the starting $\mathrm{R}$ or $\mathrm{E}$ cell concentrations were applied to the upper compartment of a CytoSelect ${ }^{\text {mit }}$ Cell Invasion chamber (Cat \#: CBA 110, Cell Biolabs). Following 48 hours of culture in the assay chambers invasive cells are able to degrade the matrix proteins in the layer, pass through the pores of the polycarbonate membrane, and adhere to the bottom ECM membrane insert. Non-invasive cells were removed from the upper chamber and invasive cells exposed on the bottom of the ECM membrane were stained according to the manufacturer's instructions and quantified by a light microscope using Metamorph imaging software.

\section{Whole transcriptome shotgun sequencing (RNA-Seq) and pathway analysis}

Whole Transcriptome Sequencing (RNA-Seq) analysis was carried out for RNA derived from cells cultured on soft PA gel and hard polystyrene (PS) substrates. Harvested cells were put in RNA protect reagents (Qiagen Inc., Valencia, CA) to preserve the integrity of RNA. Total RNA samples were isolated from E and R HCT-8 cells using RNeasy Mini Kit (Qiagen Inc., Valencia, CA) according to manufacturer's recommendation. Briefly, confluent $\mathrm{E}$ cells at passage 18 (approximately $3-4 \times 10^{6}$ cells per P60 polystyrene dish) following 3 or 17 days of culture were rinsed with PBS followed by scraping off the cell layer in $750 \mu \mathrm{l}$ of RNA Protect. Cells were pelleted by centrifugation. Cell pellets were suspended in $350 \mathrm{ul}$ of RLT buffer from the RNeasy kit and were homogenized using the Qiashredder spin column. The homogenized cell lysate effluent from the Qiashredder spin column was then processed as per RNeasy mini kit manufacturer's directions, which included a gDNA eliminator column and total RNA was obtained in water. Likewise, total RNA from E cells grown on $20 \mathrm{kPA}$ polyacrylamide gels for 3 days was obtained. Total RNA from R cells was harvested following growth on $20 \mathrm{kPA}$ polyacrylamide gels for 15 days followed by filtering through $40 \mu \mathrm{m}$ mesh (BD Falcon \#352340) and expanded by culture on PS for 4 days. Concentrations and initial quality assessment of the RNA were determined by measuring absorbance at 260, 230 and $280 \mathrm{~nm}$. RNA quality of the 
samples was checked using Nano6000/Pico bioanalyzer chips (Agilent 2100 Bioanalyzer, Santa Clara, CA) at the Keck Center for Comparative and Functional Genomics, University of Illinois. These RNA samples are denoted as PS3 (culture on polystyrene for 3 days), PS17 (culture on polystyrene for 17 days), Gel3 (culture on polyacrylamide for 3 days), and $\mathrm{R}$ (cells harvested after 15 days of culture on $20 \mathrm{kPA}$ gels and expanded on PS for 4 days).

Following RNA isolation an additional DNase1 digestion step was performed to ensure that the samples are free from any contaminated with genomic DNA. Libraries are prepared using TruSeq RNA Sample Prep kits (Illumina Inc, San Diego, CA) and sequencing is performed at the King Abdullah University of Science and Technology (KAUST), Saudi Arabia, using an Illumina HiSeq2000 sequencer. Sequence run was then set up for 100, 7, and 100 cycles for Read1, Index Read and Read2, respectively on HiSeq2000 using TruSeq SBS V3.0 kit. Off Line Base (OLB) calling, demultiplexing and FastQ files were then generated using CASAVA 1.8.2 (Illumina Inc. San Diego, CA, USA).

$\mathrm{E}$ and $\mathrm{R}$ cell RNA-Seq reads are trimmed to remove poor quality sequences in Roy J. Carver Biotechnology Center, UIUC. Sequence files are mapped against the Human Genome (hg19) using TopHat tool such that only uniquely mapped reads are reported and used for further data analysis. Splice junctions are automatically determined by TopHat, with the provided guidance of annotated gene models (GTF file) obtained mainly from Ensembl. In this analysis, all three splice sites, "GT-AG", "GC-AG" and "AT-AC" will be considered. All splicing junctions supported by at least one high-quality mapped read will be kept. The resulting alignment data from Tophat are then fed to an assembler, Cufflinks, to assemble aligned RNA-Seq reads into parsimonious set of transcripts and to estimate their abundances and test for differential expression and regulation in RNA-Seq samples. Cufflinks is used to address the common issue of read alignment to multiple isoforms of the same gene or multiple transcripts within the same genetic locus in the assembly by performing maximum likelihood estimation based on a numerical optimization algorithm for calculating FPKM. Cufflinks is executed for each sample separately using their alignment file (.BAM file) and hg19 annotation file (.gtf file), which results in a 'transcripts. gtf' files for each sample. Cuffcompare tool from Cufflinks package is used to track the cufflinks transcripts (transcripts.gtf) across multiple experiments and compare the assembled transcripts across all samples to the reference annotation file (.gtf file) and to give a combined (.gtf) file. Cuffdiff tool from Cufflinks package will be used to find significant changes in gene expression. This tool is executed using alignment files of two samples being compared and using combined .gtf files generated from previous cuffcompare tool. Transcript abundances are measured in Fragments Per Kilobase of exon per Million fragments mapped (FPKM), which originate from RPKM (Reads per Kilobase per Million). Student's t-test was then used to find significantly differentially expressed transcripts, with the test statistic (fold expression) derived from the log ratio of FPKM values when comparing two samples. In an attempt to bias the results to screen for gene expression changes primarily resulting from the transition from an $\mathrm{E}$ to $R$ cell induced by a change in substrate mechanical stiffness rather than variance in general cell culture conditions, genes were scored as differentially expressed only if they were seen simultaneously in three different comparisons ( $R$ vs PS3, R vs Gel3 and R vs PS17). These three comparisons represent comparing cells that have undergone $\mathrm{E}$ to $\mathrm{R}$ transition ( $\mathrm{R}$ cells) with $\mathrm{E}$ cells that were exposed to either polystyrene (hard) or polyacrylamide gels (soft) substrates for varying culture times but that did not undergo E to $\mathrm{R}$ transition. Preliminary pathway analysis was carried out using the online Panther software with focus on the genes with differential expression comparison levels lower than q-value of 0.05 and according to the criteria mentioned above.

\section{RT-qPCR}

First strand c-DNA was synthesized from total RNA using Superscript III catalog \# 18080-051 (Invitrogen Life Technologies, Grand Island, NY) according to manufacturer's direction. Quantitative RT-PCR (RT-qPCR) was performed using SsoFast Eva Green Supermix system (catalog number 172-5200, Bio-Rad Laboratories, Hercules, CA) according to manufacturer's directions. Samples were heated at $95^{\circ} \mathrm{C}$ for $15 \mathrm{~min}$ then subjected to 40 thermocycles $\left(95^{\circ} \mathrm{C}\right.$ for 5 seconds, $60^{\circ} \mathrm{C}$ for $10 \mathrm{sec}-$ onds, $72^{\circ} \mathrm{C}$ for 30 seconds, followed by a 60 to $95^{\circ} \mathrm{C}$ melt curve) of PCR amplification using an MJ Mini Opticon real time PCR detection system (Bio-Rad laboratories, Hercules, CA). Triplicate reactions were performed for each sample. PCR products were analyzed using Ethidium Bromide stained $2 \%$ agarose gels (E-gels, Invitrogen, catalog number G5018-02) and a $50 \mathrm{bp}$ ladder standard from Biolabs N0473G.

Primer design was done using program Primer 3 (http:// biotools.umassmed.edu/bioapps/primer3_www.cgi). Cross reaction of primers with the genes was excluded by comparison of the sequence of interest with a database (Blast, US National Centre for biotechnology Information, Bethesda, MD Expression of 5 homo sapiens genes (Glyceraldehyde -3- Phosphate dehydrogenase, (GAPDH); Aldehyde dehydrogenase 3 family, member A1 (ALDH3A1); tensin 4 (TNS4); claudin 2 (CLDN2), transcript variant 1; aldo-keto reductase family 1 , member $\mathrm{B} 10$ (aldose reductase) (AKR1B10) was determined by real time RCR as detailed above. The detection of homo sapiens GAPDH 
employed a pair of primers 5'-CCAGCCGAGCCAC ATCGCTC-3'F and 5' -CCCCCTGCAAATGAGCCC CA-3'R prepared by Integrated DNA Technologies, expected amplicon size $370 \mathrm{bp}$. The following primer pairs were obtained from Thermo Fisher, Hanover Park, IL manufacturer, Operon Biotechnologies Inc: Homo sapiens Aldehyde dehydrogenase 3 family, member A1 (ALDH3A1) RNA was detected using a pair of primers 5' -TCAGCAGGACGAGCTCTACA-3' F and 5'-GCA GGCTCGCCATGTTCTCA-3'R; expected amplicon size $170 \mathrm{bp}$. Homo sapiens tensin 4 (TNS4) RNA was detected using a pair of primers 5 '-GGACCCCAGAG GACCTTGACTCCTA-3' $F$ and 5' -ACCACTGCGAA GGGAGCCGA-3'R;expected amplicon size 281 bp. Homo sapiens claudin 2 (CLDN2), transcript variant 1 RNA was detected using a pair of primers $5^{\prime}$-TGGC CTCTCTTGGCCTCCAACTTGT-3' F and 5'-GCCTGG ATGTCAGCGGGCAG-3'R, amplicon size 235 bp. Homo sapiens aldo-keto reductase family 1 , member B10 ( aldose reductase) (AKR1B10) RNA was detected using a pair of primers 5'-TGTGGGCCTGGGCACTTGGA-3' $\mathrm{F}$ and 5'-GGTCCTCCCGCTTCACAGCC-3'R, amplicon obtained by this primer pair was $173 \mathrm{bp}$. Normalized gene expression $(\Delta \Delta \mathrm{CT})$ ) of (ALDH3A1), (TNS4), (CLDN2), and (AKR1B10) in $E$ vs $R$ cells relative to GAPDH reference gene were calculated following primer efficiency calibration for GADPH using Bio-Rad CFX Manager Software version 1.5 .

\section{ALDH, actin, and nuclear immunofluorescent staining}

ALDEFLUOR $^{\mathrm{Tm}}$ reagent kit was used to identify human cancer cells that express high levels of the enzyme aldehyde dehydrogenase (ALDH). Cultures were added with $5 \mu \mathrm{L}$ of ALDEFLUOR ${ }^{\mathrm{m} w}$ reagent per milliliter of cells and incubated for 30 to $60 \mathrm{~min}$ at $37^{\circ} \mathrm{C}$ followed by storage on ice or at $4^{\circ} \mathrm{C}$. An epi-fluorescent microscope and the Metamorph imaging software were used to quantify stained $\mathrm{E}$ and $\mathrm{R}$ cells. Cultures for actin and nuclear staining were fixed with $4 \%$ paraformaldehyde at $37 \mathrm{oC}$ for $30 \mathrm{~min}$ and permeabilized using $0.1 \%$ Triton $\times 100$ for $15 \mathrm{~min}$. Cultures were kept in HPLC (high performance liquid chromatography) Grade Methanol at $-20^{\circ} \mathrm{C}$ in a closed glass vial for $15 \mathrm{~min}$. DAPI was used for staining the cell nuclei. Rhodamine phalloidin (520/650, red) served as a fluorescent conjugate to bind specifically to F-actin filaments. Image-iT FX signal enhancer (Cat. No. I36933; Invitrogen) was used throughout the staining process to enhance the imaging signal-to-noise ratio and diminish non-specific antibody binding [74-76].

\section{Reactive oxygen species (ROS) detection and imaging}

The carboxy-H2DCFDA (C25H16Cl2O9; No.: C400; Invitrogen, Molecular Probes), carboxy derivative of fluorescein, was used as cell-permeating indicator for reactive oxygen species (ROS). Mechanistically, the non-fluorescent 5-(and-6)-carboxy-2', 7'-dichlorodihydrofluorescein diacetate (carboxy-H2DCFDA) permeates live cells to enter the cytoplasm where it is deacetylated by nonspecific intracellular esterases. In the presence of nonspecific ROS in targeted cells, the reduced fluorescein compound is oxidized and emits green fluorescence (504/530, Figure 4a) $[78,79]$. An optimal dye-loading concentration was empirically determined as $5.0 \mu \mathrm{M}$ (504/530, green) for HCT-8 cell monolayers. The working solution was freshly prepared using high quality anhydrous dimethylsulfoxide (DMSO) prior to experiments, and the excess diluted probe was discarded at the end of the experiment. The phenol-red-free HCT-8 growth medium (Catalog number R8755, Sigma-Aldrich, St. Louis, MO) was removed, replaced by the working solution, and incubated at $37^{\circ} \mathrm{C}$ for $15 \mathrm{~min}$ (empirically determined as optimal). Following this incubation, the working solution was removed and replaced with pre-warmed growth medium followed by confocal microscopy imaging after 5-10 min recovery time.

\section{Laser confocal microscopy imaging and analysis}

The actin structures and ROS expression patterns of HCT-8 cells were imaged with a Leica SP2 confocal microscopy (Leica SP2, Heidelberg, Germany) with Amira (Advanced3DVisualization and Volume Modeling) software. An inverted optical microscope (Olympus IX81, Olympus America) and a SPOT camera were used to record living cell behavior using phase-contrast microscopy. A high-resolution Piezo-controlled microscope stage was used for multi-spot time-lapse video recording. The image analysis and processing were done using ImageJ, Matlab 7, Photoshop CS2 and Microsoft Excel 2012.

\section{Anchorage-independent growth and viability assay}

PA gels with $20 \mathrm{kPa}$ stiffness were prepared on glassslide with grids (EMS Inc.) following the procedures described above, but without any surface ECM functionalization, i.e. fibronectin or laminin (BD Bioscience). These non-functionalized surfaces prevent any specific or non-specific cell anchorage. Single E and R cells were separately cultured on gels at a starting density of $1 \times 10^{5}$ cells per gel. Three independent repeats were carried out with 4 gels for each cell type. The anchorage-free survival of cells was confirmed by daily imaging. Care was taken during gentle medium change to minimize cell loss, though a few cells in suspension were unavoidably removed. The formation of spheroid colonies from single cells, the survival of single cells, and the growth of cells in suspension were observed and quantified with the assistance of gridded glass-slides. After 1-week of culture, a $2.0 \mathrm{ml}$ aliquot of the cell suspension containing both spheroids and single cells was harvested per gel following gentle shaking to ensure unbiased sample acquisition, and examined 
between 2 transparent, sterile glass-slides under a light microscope. A $0.4 \%$ sterile filtered Trypan Blue solution (Sigma-Aldrich, St. Louis, MO) was applied in the cell medium to quantify the percentage of viable cells. For each $2 \mathrm{ml}$ sample, 40 spots were imaged and the numbers of live/dead cells were counted. Percentage of viable cells is defined as number of viable (unstained) cells vs. total number of cells. Data for single cells and spheroids are compared respectively.

\section{Animal models and histological results}

All animal procedures were approved by the University of Illinois Institutional Animal Care and Use Committee. Athymic nude mice (5-6 weeks old) from Charles River Laboratory were acclimated for five weeks and fed a modified AIN93A diet (calories 11\%, fat 39\%, carbohydrates $50 \%$, proteins $20 \%$ ). Animals were surgically injected in the spleen with either HCT-8E or HCT-8R cells. Mice were anaesthetized with isoflurane and the spleen was exteriorized via abdominal midline incision. Prior to the procedure, HCT-8E and HCT-8R cells were washed with PBS, harvested by trypsinization, and suspended in PBS. Each animal was injected with one million cells suspended in $50 \mu \mathrm{l}$ of PBS. The muscle wall of the abdomen was closed with absorbable suture. The skin incision was then closed using a sterile stainless steel wound clip. Animals were sacrificed 9-10 weeks after cancer cell injection. Mice were euthanized under anesthesia by exsanguination. During the necropsy, the liver, lungs, spleen and other implantation sites were sampled, fixed in 10\% buffered formalin and embedded in paraffin. Tissue sections $(5 \mu \mathrm{m})$ were stained with H\&E. Six representative sections of the liver (left lateral lobe, right and left median lobes) and one section of the spleen, lungs, and all other tumor implantation sites were evaluated histologically by a certified veterinary pathologist.

\begin{abstract}
Abbreviations
E-cell: Adhesive epithelial type; R-cell: Rounded dissociated type; RNAseq: RNA Sequencing; ROS: Reactive oxygen species; PS: Polystyrene; PA: Polyacrylamide; ALDH3A1: Aldehyde dehydrogenase 3 family member A1; TENS4: Tensin 4; CLDN2: Claudin 2; AKR1B10: Aldo-keto reductase family 1, member B10; ALDH: Aldehyde dehydrogenase; AFM: Atomic force microscopy; GADPH: Glyceraldehyde -3- Phosphate dehydrogenase; EMT: Epithelial-to-mesenchymal transition; FPKM: Fragments Per Kilobase of exon per Million fragments mapped; DIC: Differential interference contrast.
\end{abstract}

\section{Competing interests}

All authors declare that they have no competing interests.

\section{Authors' contributions}

XT participated in the design of the study, carried out most of the in vitro experiments, AFM, statistical analysis and drafted the manuscript. TBK carried out the cell culture and $\mathrm{qPCR}$ validation experiments and helped draft the manuscript. QL carried out the animal trial, data analysis and helped to draft the manuscript. SA performed all technical aspects of the RNA-seq experiments and assisted in the bioinformatics analyses in collaboration with the University of Illinois Roy J. Carver Biotechnology Center. SL histologically evaluated the paraffin-embedded slides and helped with the editing of the manuscript. HC designed and participated in the animal study and helped to draft the manuscript. MA and WWL assisted in initial study design of the
RNA-seq and qPCR validation experiments. TAF and MSK made substantial contribution to the conception of the study, participated in its design and coordination, interpretation of the RNA-seq data and helped to draft the manuscript. All authors read and approved the final manuscript.

\section{Acknowledgement}

X. T. was funded from NSF Grant 0965918 IGERT: Training the Next Generation of Researchers in Cellular and Molecular Mechanics and BioNanotechnology. We gratefully thank Mrs. Ketaki Bhide, Mr. Ravikiran Donthu, Dr. Jyothi Thimmapuram and Dr. Jenny Drnevich Zadeh for their effective help on RNA-Seq data processing at the University of Illinois Roy J. Carver Biotechnology Center. Insightful discussions with Prof. Norm E. Sladek (Masonic Cancer Center, Univ. of Minnesota), Prof. John Katzenellenbogen, and Prof. Fei Wang (UIUC) are highly appreciated. We also thank Dr. Mayandi Sivaguru for the invaluable training with immunocytochemical staining and confocal microscopy imaging at the Institute for Genomic Biology (IGB), UIUC. Assistance in PA gels preparations by Ms. Jana DiDomenico, Ms. Linna Guan, Ms. Vivian E Jung, Mr. Joe Laskowski and Mr. Stephan Lane are gratefully acknowledged.

The work was supported by the grants: National Science Foundation 1002165, 0965918 IGERT, National Institute of Health RO1 083272-03, and UIUC Interdisciplinary Innovation Initiative Program grant \#12035. We acknowledge the assistance of Dr. Scott MacLaren (Frederick Seitz Materials Research Laboratory (MRL), UIUC) with the atomic force microscopy (AFM) experiments, and Ms. Linna Guan (MSE, UIUC) and Ms. Vivian Jung (MCB, UIUC) with the preparation of PA gel substrates and cell culture.

X. T. was funded from NSF Grant 0965918 IGERT: Training the Next Generation of Researchers in Cellular and Molecular Mechanics and BioNanotechnology. We gratefully thank Mrs. Ketaki Bhide, Mr. Ravikiran Donthu, Dr. Jyothi Thimmapuram and Dr. Jenny Drnevich Zadeh for their effective help on RNA-Seq data processing at the University of Illinois Roy J. Carver Biotechnology Center. Insightful discussions with Prof. Norm E. Sladek (Masonic Cancer Center, Univ. of Minnesota), Prof. John Katzenellenbogen, and Prof. Fei Wang (UIUC) are highly appreciated. We also thank Dr. Mayandi Sivaguru for the invaluable training with immunocytochemical staining and confocal microscopy imaging at the Institute for Genomic Biology (IGB), UIUC. Assistance in PA gels preparations by Ms. Jana DiDomenico, Ms. Linna Guan, Ms. Vivian E Jung, Mr. Joe Laskowski and Mr. Stephan Lane are gratefully acknowledged.

\section{Author details}

${ }^{1}$ Department of Mechanical Science and Engineering, College of Engineering, University of Illinois at Urbana-Champaign, 206 W. Green St, Urbana 61802, Illinois, USA. ${ }^{2}$ Department of Pathobiology, College of Veterinary Medicine, University of Illinois at Urbana-Champaign, 2001 S. Lincoln Ave, Urbana 61802, Illinois, USA. ${ }^{3}$ Department of Food Science and Human Nutrition and Division of Nutritional Sciences, University of Illinois at Urbana-Champaign, 905 S. Goodwin Ave, Urbana 61802, Illinois, USA. ${ }^{4} 4700$ King Abdullah University of Science and Technology, Thuwal 23955-6900, Kingdom of Saudi Arabia.

Received: 20 November 2013 Accepted: 2 April 2014 Published: 29 May 2014

\section{References}

1. Weinberg RA: The Biology of Cancer. New York: Garland Science; 2007.

2. Gupta GP, Massague J: Cancer metastasis: building a framework. Cell 2006, 127:679-695.

3. Hanahan D, Weinberg RA: Hallmarks of cancer: the next generation. Cell 2011, 144:646-674

4. Bissell MJ, Radisky D: Putting tumours in context. Nat Rev Cancer 2001, 1:46-54.

5. Vogelstein B, Kinzler KW: Cancer genes and the pathways they control. Nat Med 2004, 10:789-799.

6. Chambers AF, Groom AC, MacDonald IC: Dissemination and growth of cancer cells in metastatic sites. Nat Rev 2002, 2:563-572.

7. Brábek J, Mierke $C T$, Rösel D, Veselý P, Fabry B: The role of the tissue microenvironment in the regulation of cancer cell motility and invasion. Cell Commun Signal 2010, 8:1-8.

8. Huang $S$, Ingber DE: Cell tension, matrix mechanics, and cancer development. Cancer Cell 2005, 8:175-176. 
9. Mareel M, Oliveira MJ, Madani I: Cancer invasion and metastasis: interacting ecosystems. Virchows Arch 2009, 454:599-622.

10. Rosenthal KL, Tompkins WAF, Frank GL, McCulloch P, Rawls WE: Variants of a human colon adenocarcinoma cell line which differ in morphology and carcinoembryonic antigen production. Cancer Res 1977, 37:4024-4030.

11. Tompkins WA, Watrach AM, Schmale JD, Schultz RM, Harris JA: Cultural and antigenic properties of newly established cell strains derived from adenocarcinomas of the human colon and rectum. J Natl Cancer Inst 1974, 52:1101-1110

12. Vermeulen SJ, Bruyneel EA, Bracke ME, Bruyne GKD, Vennekens KM, Vleminckx KL, Berx GJ, Roy FM, Mareel MM: Transition from the noninvasive to the invasive phenotype and loss of a-Catenin in human colon cancer cells. Cancer Res 1995, 55:4722-4728.

13. Vermeulen SJ, Chen TR, Speleman F, Nollet F, Roy FMV, Mareel MM: Did the four human cancer cell lines DLD-1, HCT-15, HCT-8, and HRT-18 originate from One and the same patient? Cancer Genet Cytogenet 1998, 107:76-79.

14. Vermeulen SJ, Nollet F, Teugels E, Vennekens KM, Malfait F, Philippe ÂJ, Speleman F, Bracke ME, Roy FM, Mareel MM: The Alpha-E-catenin gene (CTNNA1) acts as an invasion-suppressor gene in human colon cancer cells. Oncogene 1999, 18:905-915.

15. Baker EL, Bonnecaze RT, Zaman MH: Extracellular matrix stiffness and architecture govern intracellular rheology in cancer. Biophys J 2009, 97:1013-1021.

16. Butcher DT, Alliston T, Weaver VM: A tense situation: forcing tumour progression. Nat Rev Cancer 2009, 9:108-122.

17. Kumar S, Weaver VM: Mechanics, malignancy, and metastasis: the force journey of a tumor cell. Cancer Metastasis Rev 2009, 28:113-127.

18. Pathak A, Kumar S: Biophysical regulation of tumor cell invasion: moving beyond matrix stiffness. Integr Biol 2011, 3:267-278.

19. Weaver VM, Petersen OW, Wang F, Larabell CA, Briand P, Damsky C, Bissell MJ: Reversion of the malignant phenotype of human breast cells in three-dimensional culture and in vivo by integrin blocking antibodies. J Cell Biol 1997, 137:231-245.

20. Wirtz D, Konstantopoulos K, Searson PC: The physics of cancer: the role of physical interactions and mechanical forces in metastasis. Nat Rev Cancer 2011, 11:512-522.

21. Levental KR, Yu H, Kass L, Lakins JN, Egeblad M, Erler JT, Fong SFT, Csiszar K, Giaccia A, Weninger W, Yamauchi M, Gasser DL, Weaver VM: Matrix crosslinking forces tumor progression by enhancing integrin signaling. Cell 2009, 139:891-906.

22. Paszek MJ, Zahir N, Johnson KR, Lakins JN, Rozenberg Gl, Gefen A, Reinhart-King CA, Margulies SS, Dembo M, Boettiger D, Hammer DA, Weaver VM: Tensional homeostasis and the malignant phenotype. Cancer Cell 2005, 8:241-254.

23. Liu J, Tan Y, Zhang H, Zhang Y, Xu P, Chen J, Poh Y-C, Tang K, Wang N, Huang $B$ : Soft fibrin gels promote selection and growth of tumorigenic cells. Nat Mater 2012, 11:734-741.

24. Califano JP, Reinhart-King CA: Substrate stiffness and cell area predict cellular traction stresses in single cells and cells in contact. Cell Mol Bioeng 2010, 3:68-75.

25. Fu J, Wang Y-K, Yang MT, Desai RA, Yu X, Liu Z, Chen CS: Mechanical regulation of cell function with geometrically modulated elastomeric substrates. Nat Methods 2010, 7:733-736.

26. Tang X, Kuhlenschmidt TB, Zhou J, Bell P, Wang F, Kuhlenschmidt MS, Saif TA: Mechanical force affects expression of an in vitro metastasis-like phenotype in HCT-8 cells. Biophys J 2010, 99:2460-2469.

27. Tang X, Wen Q, Kuhlenschmidt TB, Kuhlenschmidt MS, Janmey PA, Saif TA: Attenuation of cell mechanosensitivity in colon cancer cells during in vitro metastasis. Plos ONE 2012, 7:e50443

28. Carpentino JE, Hynes MJ, Appelman HD, Zheng T, Steindler DA, Scott EW, Huang EH: Aldehyde dehydrogenase-expressing colon stem cells contribute to tumorigenesis in the transition from colitis to cancer. Cancer Res 2009, 69:8208-8215.

29. Huang EH, Hynes MJ, Zhang T, Ginestier C, Dontu G, Appelman H, Fields JZ, Wicha MS, Boman BM: Aldehyde dehydrogenase 1 is a marker for normal and malignant human colonic stem cells (SC) and tracks SC overpopulation during colon tumorigenesis. Cancer Res 2009, 69:3382-3389.

30. Townsend AJ, Leone-Kabler S, Haynes RL, Wu Y, Szwed L, Bunting KD: Selective protection by stably transfected human ALDH3A1 (but not human ALDH1A1) against toxicity of aliphatic aldehydes in V79 cells. Chem Biol Interact 2001, 130:261-273.
31. Albasri A, Seth R, Jackson D, Benhasouna A, Crook S, Nateri AS, Chapman R, Ilyas M: C-terminal Tensin-like (CTEN) is an oncogene which alters cell motility possibly through repression of E-cadherin in colorectal cancer. J Pathol 2009, 218:57-65.

32. Dhawan P, Ahmad R, Chaturvedi R, Smith J, Midha R, Mittal M, Krishnan M, Chen X, Eschrich S, Yeatman T, Harris RC, Washington MK, Wilson KT, Beauchamp RD, Singh AB: Claudin-2 expression increases tumorigenicity of colon cancer cells: role of epidermal growth factor receptor activation. Oncogene 2011, 30:3234-3247.

33. Katz M, Amit I, Citri A, Shay T, Carvalho S, Lavi S, Milanezi F, Lyass L, Amariglio N, Jacob-Hirsch J, Ben-Chetrit N, Tarcic G, Lindzen M, Avraham R, Liao YC, Trusk P, Lyass A, Rechavi G, Spector NL, Lo SH, Schmitt F, Bacus SS, Yarden Y: A reciprocal tensin-3-cten switch mediates EGF-driven mammary cell migration. Nat Cell Biol 2007, 9:961-969.

34. Liao Y-C, Chen N-T, Shih Y-P, Dong Y, Lo SH: Up-regulation of C-terminal Tensin-like molecule promotes the tumorigenicity of colon cancer through $\beta$-catenin. Cancer Res 2009, 69:4563.

35. Mooney SM, Rajagopalan K, Williams BH, Zeng Y, Christudass CS, Li Y, Yin B, Kulkarni $P$, Getzenberg RH: Creatine kinase brain overexpression protects colorectal cells from various metabolic and non-metabolic stresses. J Cell Biochem 2011, 112:1066-1075.

36. Cavallaro U, Christofori G: Cell adhesion and signalling by cadherins and Ig-CAMs in cancer. Nat Rev Cancer 2004, 4:118-132.

37. Thiery JP, Acloque H, Huang RYJ, Nieto MA: Epithelial-mesenchymal transitions in development and disease. Cell 2009, 139:871-890.

38. Matsunaga T, Wada Y, Endo S, Soda M, El-Kabbani O, Hara A: Aldo-Keto reductase $1 \mathrm{~B} 10$ and its role in proliferation capacity of drug-resistant cancers. Front Pharmacol 2012, 3:1-11.

39. Moreb JS: Aldehyde dehydrogenase as a marker for stem cells. Curr Stem Cell Res Ther 2008, 3:237-246.

40. Yan R, Zu X, Ma J, Liu Z, Adeyanju M, Cao D: Aldo-keto reductase family 1 B10 gene silencing results in growth inhibition of colorectal cancer cells: Implication for cancer intervention. Int J Cancer 2007, 121:2301-2306.

41. Black W, Chen Y, Matsumoto A, Thompson DC, Lassen N, Pappa A, Vasiliou $\checkmark$ : Molecular mechanisms of ALDH3A1-mediated cellular protection against 4-hydroxy-2-nonenal. Free Radic Biol Med 2012, 52:1937-1944.

42. Ginestier C, Hur MH, Charafe-Jauffret E, Monville F, Dutcher J, Brown M, Jacquemier J, Viens P, Kleer C, Liu S, Schott A, Hayes D, Birnbaum D, Wicha MS, Dontu G: ALDH1 is a marker of normal and malignant human mammary stem cells and a predictor of poor clinical outcome. Cell Stem Cell 2007, 1:555-567.

43. Ma I, Allan AL: The role of human aldehyde dehydrogenase in normal and cancer stem cells. Stem Cell Rev Rep 2011, 7:292-306.

44. Fruehauf JP, L Meyskens F: Reactive oxygen species: a breath of life or death? Clin Cancer Res 2007, 13:789-794.

45. Konorev EA, Zhang H, Joseph J, Kennedy MC, Kalyanaraman B: Bicarbonate exacerbates oxidative injury induced by antitumor antibiotic doxorubicin in cardiomyocytes. Am J Physiol Heart Circ Physiol 2000, 279:2424-2430.

46. Manda G, Nechifor MT, Neagu T-M: Reactive oxygen species, cancer and anti-cancer therapies. Curr Chem Biol 2009, 3:342-366.

47. Maurer BJ, Metelitsa LS, Seeger RC, Cabot MC, Reynolds CP: Increase of ceramide and induction of mixed apoptosis/necrosis by $\mathrm{N}$-(4-Hydroxyphenyl)-retinamide in Neuroblastoma cell lines. J Nat Cancer Inst 1999, 91:1138-1146.

48. Waris $\mathrm{G}$, Ahsan $\mathrm{H}$ : Reactive oxygen species: role in the development of cancer and various chronic conditions. J Carcinog 2006, 5:1-8.

49. Valastyan S, Weinberg RA: Tumor metastasis: molecular insights and evolving paradigms. Cell 2011, 147:275-292.

50. Mehlen P, Puisieux A: Metastasis: a question of life or death. Nat Rev Cancer 2006, 6:449-458.

51. Kim Y-N, Koo KH, Sung JY, Yun U-J, Kim H: Anoikis resistance: an essential prerequisite for tumor metastasis. Int J Cell Biol 2012 2011:1-11.

52. Zhan M, Zhao H, Han ZC: Signalling mechanisms of anoikis. Histol Histopathol 2004, 19:973-983.

53. Simpson CD, Anyiwe K, Schimmer AD: Anoikis resistance and tumor metastasis. Cancer Lett 2008, 272:177-185.

54. Kantak SS, Kramer RH: E-cadherin regulates anchorage-independent growth and survival in oral squamous cell carcinoma cells. J Biol Chem 1998, 273:16953-16961. 
55. Butler JP, Fredberg JJ, Ingber DE, Wang N: Method and system for measurement of mechanical properties of molecules and cells. US Patent Number US5486457, 2 March 1995.

56. Cross SE, Jin Y-S, Rao J, Gimzewski JK: Nanomechanical analysis of cells from cancer patients. Nat Nanotechnol 2007, 2:780-783.

57. Guck J, Schinkinger S, Lincoln B, Wottawah F, Ebert S, Romeyke M, Len D, Erickson HM, Ananthakrishnan R, Mitchell D, Kas J, Ulvick S, Bilby C: Optical deformability as an inherent cell marker for testing malignant transformation and metastatic competence. Biophys J 2005, 88:3689-3698.

58. Plodinec M, Loparic M, Monnier CA, Obermann EC, Zanetti-Dallenbach $\mathrm{R}$, Oertle P, Hyotyla JT, Aebi U, Bentires-Alj M, Lim RYH, Schoenenberger C-A: The nanomechanical signature of breast cancer. Nat Nanotechnol 2012, 7:757-765.

59. Suresh S, Spatz J, Mills JP, Micoulet A, Dao M, Lim CT, Beil M, Seufferlein T: Connections between single-cell biomechanics and human disease states: gastrointestinal cancer and malaria. Acta Biomater 2005, 1:15-30.

60. Deng S, Yang X, Lassus H, Liang S, Kaur S, Ye Q, Li C, Wang L-P, Roby KF, Orsulic S, Connolly DC, Zhang Y, Montone K, Butzow R, Coukos G, Zhang L: Distinct expression levels and patterns of stem cell marker, aldehyde dehydrogenase isoform 1 (ALDH1), in human epithelial cancers. PLOS ONE 2010, 5:1-11.

61. Marcato P, Dean CA, Pan D, Araslanova R, Gillis M, Joshi M, Helyer L, Pan L, Leidal A, Gujar S, Giacomantonio CA, Lee PW: Aldehyde dehydrogenase activity of breast cancer stem cells is primarily due to isoform ALDH1A3 and its expression is predictive of metastasis. Stem Cell 2011, 29:32-45.

62. Sl'adek NE: Human aldehyde dehydrogenases: potential pathological, pharmacological, and toxicological impact. J Biochem Mol Toxicol 2003 $17: 7-23$.

63. Sullivan JP, Spinola M, Dodge M, Raso MG, Behrens C, Gao B, Schuster K, Shao C, Larsen JE, Sullivan LA, Honorio S, Xie Y, Scaglioni PP, DiMaio JM, Gazdar AF, Shay JW, Wistuba II, Minna JD: Aldehyde dehydrogenase activity selects for lung adenocarcinoma stem cells dependent on notch signaling. Cancer Res 2010, 70:9937-9948.

64. Zhang Q, Taguchi A, Schliekelman M, Wong C-H, Chin A, Kuick RE, Misek D, Hanash S: Comprehensive proteomic profiling of aldehyde dehydrogenases in lung adenocarcinoma cell lines. Int J Proteomics 2011, 2011:1-8.

65. Muzio G, Maggiora M, Paiuzzi E, Oraldi M, Canut RA: Aldehyde dehydrogenases and cell proliferation. Free Radic Biol Med 2012, 52:735-746.

66. Bertucci F, Salas S, Eysteries S, Nasser V, Finetti P, Ginestier C, CharafeJauffret E, Loriod B, Bachelart L, Montfort J, Victorero G, Viret F, Ollendorff V, Fert V, Giovaninni M, Delpero JR, Nguyen C, Viens P, Monges G, Birnbaum D, Houlgatte R: Gene expression profiling of colon cancer by DNA microarrays and correlation with histoclinical parameters. Oncogene 2004, 23:1377-1391.

67. Al-Ghamdi S, Albasri A, Cachat J, Ibrahem S, Muhammad BA, Jackson D, Nateri AS, Kindle KB, llyas M: Cten is targeted by Kras signalling to regulate cell motility in the colon and pancreas. PlOS ONE 2011, 6:1-8.

68. Hu G, Chong RA, Yang Q, Wei Y, Blanco MA, Li F, Reiss M, Au JL-S, Haffty BG, Kang $Y:$ MTDH activation by $8 q 22$ genomic gain promotes chemoresistance and metastasis of poor-prognosis breast cancer. Cancer Cell 2009, 15:9-20.

69. Berger MJ, Minnerath SR, Adams SD, Tigges BM, Sprague SL, McKenna DH Jr: Gene expression changes with differentiation of cord blood stem cells to respiratory epithelial cells: a preliminary observation. Stem Cell Res Ther 2011, 2:1-8.

70. Khanna M, Chen C-H, Kimble-Hill A, Parajuli B, Perez-Miller S, Baskaran S, Kim J, Dria K, Vasiliou V, Mochly-Rosen D, Hurley TD: Discovery of a novel class of covalent inhibitor for aldehyde dehydrogenases. J Biol Chem 2011, 286:43486-43494.

71. Rekha GK, Sreerama L, Sladek NE: Intrinsic cellular resistance to oxazaphosphorines exhibited by a human colon carcinoma cell line expressing relatively large amounts of a class-3 aldehyde dehydrogenase. Biochem Pharmacol 1994, 48:1943-1952.

72. Tang X, Cappa T, Kuhlenschmidt T, Kuhlenschmidt M, Saif T: Specific and non-specific adhesion in cancer cells with various metastatic potentials. In Mechanobiology of Cell-Cell and Cell-Matrix Interactionss. Edited by Johnson AW, Harley B. New York: Springer US; 2011:105-122.

73. Tang X, Bajaj P, Bashir R, Saif TA: How far cardiac cells can see each other mechanically. Soft Matter 2011, 7:6151-6158.

74. Tang $X$, Ali MY, Saif MTA: A novel technique for micro-patterning proteins and cells on polyacrylamide gels. Soft Matter 2012, 8:7197-7206.
75. Bajaj $P$, Tang $X$, Saif TA, Bashir R: Stiffness of the substrate influences the phenotype of embryonic chicken cardiac myocytes. J Biomed Mater Res A 2010, 95:1261-1269

76. Cha C, Jeong JH, Tang X, Zill AT, Prakash YS, Zimmerman SC, Saif TA Kong H: Top-down synthesis of versatile polyaspartamide linkers for single-step protein conjugation to materials. Bioconjug Chem 2011, 22:2377-2382

77. Dong R, Jensen TW, Engberg K, Nuzzo RG, Leckband DE: Variably elastic hydrogel patterned via capillary action in microchannels. Langmuir 2007, 23:1483-1488

78. Brandt R, Keston AS: Synthesis of diacetyldichlorofluorescin: a stable reagent for fluorometric analysis. Anal Biochem 1965, 11:6-9.

79. Jakubowski W, Bartosz G: 2,7-dichlorofluorescin oxidation and reactive oxygen species: what does it measure? Cell Biol Int 2000, 24:757-760.

doi:10.1186/1476-4598-13-131

Cite this article as: Tang et al:: A mechanically-induced colon cancer cell population shows increased metastatic potential. Molecular Cancer 2014 13:131.

\section{Submit your next manuscript to BioMed Central and take full advantage of:}

- Convenient online submission

- Thorough peer review

- No space constraints or color figure charges

- Immediate publication on acceptance

- Inclusion in PubMed, CAS, Scopus and Google Scholar

- Research which is freely available for redistribution 